\title{
Regional Resilience in Italy: A Very Long-run Analysis ^
}

\author{
by \\ ROBERTO CELLINI ${ }^{a}$ and GIANPIERO TORRISI ${ }^{b}$ \\ ${ }^{a}$ University of Catania, Department of Economics and Business; Catania, Italy; \\ ${ }^{b}$ University of Portsmouth, Economics and Finance, Portsmouth Business School; \\ Portsmouth, U.K.
}

\begin{abstract}
Resilience is a concept derived from engineering and ecology relating to the way in which systems react to, and recover from, shocks. According to several recent analyses, different 'resilience behaviours' are able to explain differences in the economic performance of regions. This study shows that this explanation is not fully convincing when applied to the Italian regions, observed in the very long run. This analysis focuses on real per capita income levels over the period 1890-2009. Only few (major) shocks emerge to have a specific impact effect differing across the regions, while the recovery experiences never differ significantly across regions. This is accounted for by systematic and persistent differences in the economic performance of Italian regions; hence, it is difficult to discern genuine differences in regional resilience behaviour.
\end{abstract}

Keywords: Regional growth; Economic resilience; Shock impact; Recovery.

JEL Classification:O40, R11, C32.

Roberto Cellini - University of Catania, Department of Economics and Business.

Corso Italia 55 - 95129 Catania - Italy;

tel.: +39-095-7537728, fax: +39-095-7537710; e-mail cellini@ unict.it

(CORRESPONDING AUTHOR)

Gianpiero Torrisi - University of Portsmouth, Department of Economics

Richmond Building, Portland Street, Portsmouth, Hampshire, PO1 3DE, U.K.

tel. +44 (0) 23928444821 e-mail Gianpiero.Torrisi@ port.ac.uk

\footnotetext{
Although the authors alone are responsible for what is written here, thanks go to Vittorio Daniele and Emanuele Felice for useful discussion on data construction and their interpretation, as well as for having made available data in electronic format. Thanks go also to Alan Collins and Tiziana Cuccia for helpful comments, and especially to Prof. Ron Martin for his kind cooperation.
} 


\section{Regional Resilience in Italy: A Very Long-run Analysis}

\section{Introduction}

Resilience is a broad concept, derived from engineering and ecological sciences, that pertains to the way in which systems react to, and recover from, shocks. Recently, the concept has been applied to the analysis of economic growth, and more specifically to regional growth. In broad terms, the basic idea is that different resilience behaviours are the reason why regions within a country show different economic growth performance (Fingleton et al., 2012; Martin, 2012).

A large body of theoretical and applied research developed over the 1980-90s, as a by-product of the success of endogenous growth theories, with respect to regional growth in many country context (Barro and Sala-i-Martin, 1991, 1992; Bernard and Durlauf, 1996, Quah, 1996; Tsionas, 2001). Some results are widely accepted: generally speaking, regional per-capita real GDP are time series integrated of order 1 (which means that shocks have a persistent effect in the time series); co-integration links among regional (and between regional and national) series do exist (meaning that long-run relationships hold among regions); convergence -whatever definition is considered- sometimes does emerge (with different speeds), but it is not the rule in several countries. In some countries, convergence is at work only for limited period of times. Arguably, the focus on 'reaction to' and 'recovery from' specific shocks has been relatively scant in that body of literature.

Considering resilience could provide an interesting interpretational key, for understanding differences across regions. For this reason, the recent study of Fingleton et al. (2012), on the U.K. regions, serves as a useful analytical point of departure and this study offers an analysis in the spirit of Fingleton et al. (2012) and Martin (2012), with reference to Italian data.

In developing this kind of exercise some methodological changes are warranted. Specifically, annual data over a very long-run period of time (1890-2009) are considered, while Fingleton et al. (2012) use quarterly data in a four-decade period (1971-2009). In this respect, pros and cons characterise the different choices; however, 
the present very long-run perspective permits analysis of regional responses to "extreme" shocks (one can think of the World Wars, for instance), and to obtain insights to the characteristics of the growth and development process in a century perspective.

Hence, the results of the present study could be of interest not only for regional economics, but also from an economic history perspective. In particular, evidence is obtained which can be useful within the long standing debate on the reasons for Italy's persistent regional economic dualism, and its historical roots. The present study relies on a data bank recently made available by Daniele and Malanima (2007), that is attracting substantial interest and is nourishing the debate on the reasons for and the roots of such Italian dualism (e.g., Felice, 2011a, 2011b; Brunetti et al. 2011).

Furthermore, the study departs from the exercise of Fingleton et al. (2012), in terms of its accounting for resilience with respect to per capita GDP data, rather than employment data.

Finally, the results from different estimation methods are provided by the present study: specifically, beyond SURE (Seemingly Unrelated Regression Equation) estimation (and the related test on parameter restrictions in order to detect differences pertaining to regional resilience), this study also presents a random-coefficient panel estimation to assess the same hypotheses with higher estimator efficiency. Yet it is found that the main conclusions remain robust to different estimators.

In overall terms this study suggests that the resilience story does not readily offer a sound explanation for different economic performances across Italian regions -as long as 'reaction to shocks' and 'recovery from shocks' only vary in very few cases across regions. That said, the methodological framework offered by the resilience story does allow the generation of some answers to a number of questions in a very simple and intuitive way. In particular, informed by the results from the model estimates produced, the following questions, among others, can be addressed: Have regions answered the same shock in the same way?, Have regions recovered from the same shock in the same way?, Is there any difference, over time, in the way in which regions reacted to, and recovered from, shocks?, Which are the regions displaying the highest (or lowest) degree of impact resistance to recessionary shock?, Which are the regions displaying the best (or worst) ability to recover from recessionary shocks?, Have the recessionary shocks played some role in shaping regional performance?, Is there a relation between 
growth performance and the way in which regions react to- and recover from- shocks? Finally, is resilience a convincing story to explain regional economic differences across the Italian regions?

The high degree of homogeneity displayed by Italian regions in the impact reaction and in the recovery from shocks, appears as somewhat surprising, given the well-known heterogeneity across these regions. Some implications about the long-run pattern of regional income dynamics can also be discerned.

The remainder of the paper is structured as follows. Section 2 sets out the ideas behind the concept of economic resilience, with specific reference to regional growth, and makes close reference to the results presented in Fingleton et al. (2011) concerning the U.K. case. Section 3 presents the Italian data that are use in this study. Given that the time series at hand are integrated of order 1, and co-integrating links emerge, this Section also discusses the meaning of 'resilience' in an environment of integrated / cointegrated time series. Section 4 presents the results concerning the resilience of Italian regions. Section 5 offers some answers to the specific research questions previously articulated in this section. Concluding remarks are offered in the final section.

\section{Economic resilience}

Regional resilience derives from the ideas of resilience developed in engineering, ecological science and, more recently, social ecology (see, respectively, Holling, 1996; Holling, 1973; and Walker et al., 2006). It refers to the ability of a subject or a complex system to recover form and position elastically, following a shock. The engineering perspective is mainly focussed on the immediate reaction of a system to shock and its subsequent recovery; the ecological perspective mainly focuses on how a shock persistently changes the system behaviour. In social sciences and in economics more specifically, both of these perspectives make sense, as long as shocks affect the economic system through their (homogenous or heterogeneous) immediate impact and recovery reaction and also the permanent performance in the long run.

With specific reference to regional economies, Fingleton et al. (2012) analysed whether different performance in (employment) dynamics across 12 U.K. regions may 
be explained by different degrees of resilience to recessionary shocks. They investigated whether the reaction to (the same) shock differ across regions, and the recovery from shock is different across regions. To this end, they previously identified recessionary shocks within the period of time under examination (simply, the quarters in which national employment exhibits a decrease), and then they evaluated whether there is any regional specificity in the reaction to shock and in the subsequent recovery.

Formally, let $y_{i t}$ denote the $\log$ of employment level in region $i$ in time $t$, with $i=1,2$ $\ldots N$ and $t=1,2, \ldots T$. The first difference of $y_{i t}$, denoted by $g_{i t}$, measures the growth rate of employment. Assume to have identified the time of the recessionary shocks (with a total number of shocks equal to $K$ ); and associate a dummy variable $D_{k}$ to each shock $(k=1,2, \ldots, . K)$; finally consider the post-recession period following each shock and associate a dummy variable $S_{k}$ to each post-recession period $\left(S_{k}\right.$ takes value 1 in each time of the post-recession period following the $k$-shock, and 0 otherwise). Operationally, in the Fingleton et al. analysis, the post-recession period lasts until the subsequent shock, but a different choice could be made, by assuming, for instance that each post-recession period has a fixed length. Thus, for any region $i$, Fingleton et al. consider the following regression:

$$
g_{i}=\alpha_{i}+\beta_{i,(1)} D_{1}+\beta_{i,(2)} D_{2}+\ldots+\beta_{i,(K)} D_{K}+\gamma_{i,(1)} S_{1}+\gamma_{i,(2)} S_{2}+\ldots+\gamma_{i,(K)} S_{K}+e_{i}
$$

They consider the system of $N$ equations as a SURE, and then compare the beta $(\beta)$ and gamma $(\gamma)$ coefficients across regions. If $\beta_{i,(k)}=\beta_{j,(k)}, \forall i, j$, then all regions have the same impact reaction to the $k$-th shock. Similarly if $\gamma_{i,(h)}=\gamma_{j,(h)}, \forall i, j$, then all regions display the same recovery effect to the $h$-th shock.

Heterogeneity across the beta and/or gamma coefficients pertaining to a specific shock, means different resilience behaviours across regions. Specifically, Fingleton et al. (2012) identify 4 shocks hitting the U.K. regions in the period 1971-2009; apart from the most recent shock, occurred in 2008 (for which the beta coefficients are equal across regions), beta coefficients differ across regions for any given shock, so that the impact reaction is found to be different across regions. On the opposite, the gamma coefficients generally appear to be equal across regions, for each post-recession period. Hence, 
Fingleton et al. (2012) conclude that U.K. regions do show different resilience to shocks, especially in consideration of the heterogeneity across the regional impact reactions. ${ }^{1}$

The present study substantially rehearses this regression exercise but applied to the Italian case. However, it departs from the choices of Fingleton et al. (2012) in a number of respects. In particular, this study considers data with annual frequency for a much longer period of time, so that it examines the behaviour of Italian regions in the very long run. On the one hand, the time frame of this study is more consistent with the interest in the long-run growth performance of regions. Moreover, cyclical components (not to mention the seasonal ones) are a less serious problem in annual data, as compared to quarterly data. However, on the other hand, the consideration of a very long period of time requires caution and check about structural stability.

Furthermore, data on income per capita are considered rather than employment. Thus there are good reasons for either choice. Fingleton et al. argue that much of the impact of a recession is borne by the labour market, and declines in employment, after recessionary shock, are larger than decline in output; thus, the issue of regional resilience assumes particular relevance in relation to how regional labour markets are affected by and recover from shock. With respect to the Italian experience, where labour markets are more rigid as compared to the U.K. case, the focus on GDP appears to be more appropriate, precisely because the reaction of labour markets are deemed to be less variable across regions, due to institutional rigidities.

\footnotetext{
${ }^{1}$ As a by-product of the analysis, Fingleton et al (2012) find that the $\alpha$ coefficients (autonomous growth) differ across regions; this amounts to say that, in general, the performances of employment growth differ across regions (conditional on the variable accounting for the impact reaction to- and recover fromshocks). Moreover, equally not surprisingly, they find that the $\beta$ coefficients concerning different shocks for one region are not equal, i.e., the null $\beta_{i,(1)}=\beta_{i,(2)}=\ldots=\beta_{i,(K)}$ is rejected for any given region, and similarly the different $\gamma$ coefficients concerning the recovery periods for any given region differ: this means that different shocks have different effects on a given region, and are associated to different specific behaviour in post-shock recoveries: this is comprehensible, since different shocks have different intensity, source, characteristic, and so on. In the second part of their analysis, Fingleton et al. (2012) consider the propagation effect of a given shock over time andacross regions, on the basis of a VECM (Vector error correction model) specification; we do not deal with this aspect in our present research, and for this reason we do not report their results here.
} 
Fingleton et al. (2012) find that the U.K. regions do differ when it comes to the impact reaction to shock (with the exception of the recent 2008/09 shock episode), while the regional behaviours do not differ in the recovery stage. However, in overall terms, they conclude that the different impact reaction to common shock allows the argument to be made that different resilience behaviour in labour markets is a relevant element in the economic experience of U.K. regions.

\section{Italian data: Regional per capita GDP in the very long run}

This analysis uses a time series of real per capita GDP computed by Daniele and Malanima (2007) for the Italian regions over the period 1890-2009. ${ }^{2}$ Even if the current Italian regions are 20 (at the NUTS II level), the Daniele and Malanima data are articulated into 16 regions, as long as 4 regions were created after the II World War. ${ }^{3}$ The Daniele and Malanima databank is the only available databank with annual observations related to regional accounting for such a long period of time for Italy.

The contribution of Daniele and Malanima is part of a lively research line, aiming at reconstructing regional data for Italy. The databank has generated an interesting debate among economic historians. The more contested issues do not concern the methodological choices of Daniele and Malanima, nor the original sources, which can be considered as generally correct (or, at least 'necessary') ${ }^{4}$, but rather the resulting general picture. The comparison of specific point data of this databank with

\footnotetext{
${ }^{2}$ In Daniele and Malanima (2007), the data are published for the period 1891-2004. The authors of the present study thank Vittorio Daniele who provided them with the time series updated till to 2009, on the basis of the subsequent data from Istat (the Italian Statistical Office). An Appendix, in electronic format, containing all data and supplementary elaborations is available from the Authors of the present study upon request.

${ }^{3}$ In the Malanima and Daniele data, which areconsidered here: Valdaosta is included in Piemonte, Trentino A.A. and Firuli V.G. are included in Veneto, and Molise is included in Abruzzo. Data reconstruction is based on the current boundaries of regions.

${ }^{4}$ Some criticism can be moved, for instance, to the 'strong' hypothesis that the national sectoral cycles have the same impact on every region, in proportion to each regional sectoral share (Felice, 2011a); or the linear interpolation in the absence of specific annual information for some series (Ciccarelli and Fenoaltea, 2010). See also Ciccarelli and Fenoaltea (2009) and Malanima and Zamagni (2010).
} 
different databanks provides evidence of its substantial correctness and reliability, but also provides hints for further interesting debates in economic history, as some surprises emerge in relation to the consolidated wisdom. For instance, the distribution of income across regions at the beginning of the time span under consideration is less dispersed as represented in other databanks (see, on this point e.g., Felice, 2011b, p. 21; Malanima and Zamagni, 2011); again, the reconstruction of Daniele and Malanima provides a more modest economic performance of Italy during the Fascist period, as compared to the acquired wisdom, and sharply increasing regional disparities.

\section{Insert about here:}

Figure 1.a,b,c.- Log of income per capita

Figure 2.- The annual growth rate of income per capita in Italy

Figure 1 presents the plot of the log of (real, per capita) GDP time series for: (a) Italy at the national level, (b) the 16 Italian regions, (c) Italy and the two richest and poorest regions (as evaluated at the beginning of the period, which correspond to the average level; namely Liguria and Lombardia on the one side, and Calabria and Sicily at the opposite end). Figure 2 presents the plot of the first difference, that is the growth rate of real per capita GDP, for the national series. Table 1 provides some descriptive statistics on the time series, while Table 2 provides evidence concerning the test of integration / co-integration among the time series at hand. In particular:

- time series of per capita GDP at the regional level, and the series at the national level, are integrated of order 1 (Table 2.I);

- if the 16 regional series are considered, co-integration with rank equal to 15 cannot be rejected; if 17 time series (namely, the 16 regional series and the national one) are considered, co-integration with rank equal to 16 can not be rejected (Table 2.III).

The above pieces of evidence suggest that only one unit root enter the national and regional series (as clearly supported also by the group unit root test reported in Table 2.II). This results is only partially different from previous results concerning Italian regions (over more restricted periods of time), which detected a slightly larger number of distinct unit root (see, e.g., Cellini and Scorcu, 1997, D'Amato and Pistoresi, 1997; De Siano and D'Uva, 2008).Under this perspective, one could affirm that the longer 
time span under consideration permits to capture the unique unit-root driving all regional series. However, whatever the time span under consideration, the substance of evidence is similar: long-run relationships between regional (and national) per capita GDP are operative in the long run, admittedly with possible different intensity or with breaks.

Moreover,

- The correlation between any regional series (of real per capita GDP levels) on the one side, and the national series on the other is larger than 0.986 in any case.

- The pair-wise correlation between the regional series (of real per capita GDP levels) are larger than 0.957 in any case.

That is, there is a very large degree of correlation among series in level. It is more surprising that an analogous degree of correlation emerges as concerns the series of growth rates:

- The correlation between any regional series (of real per capita GDP levels) on the one side, and the national series on the other is larger than 0.878 in any case.

- The pairwise correlation between the regional series (the growth rate of real per capita GDP levels) are larger than 0.772 in any case.

\section{Insert about here:}

Table 1. - Descriptive statistics on time series, Italy and the regions

Table 2. - Results on integration and co-integration of regional time series

These pieces of evidence provide support in considering the first difference of (log) GDP in the analysis that follows: this study takes for granted that regional time series are integrated of order 1 , with the presence of long-run links -as documented by a large body of available research (see De Siano and D'Uva, 2008, and the references therein), and consistently with the evidence here provided by Table 2 . The main interest in the present analysis is in evaluating whether different resilience behaviours play some role, firstly, in shaping the short-run dynamics -and for this reason it makes sense to focus on the series in first-difference; secondly, in analysing whether resilience can be considered responsible for the different growth performance of regions: also in this part of the analysis the focus will be on the growth rate of GDP, taking it as the indicator of 
regional economic performance. Considerations on the level of time series will be left for a final stage of our analysis.

\section{Results on regional economic resilience}

\subsection{Indentifying the recessionary shock}

Following Fingleton et al. (2012), the present study identifies the years in which the national GDP growth rate is negative as years of 'recessionary shocks'. More specifically, the present study considers recessionary shocks the years in which a decrease (of per capita income, in this case) larger than $0.1 \%$ occurs; moreover, it consolidates in one shock the shocks occurring in subsequent years. As a consequence, the following 14 recessionary shocks are detected on the Italian data, over the 118-year period under examination: 1892, 1910, 1914/15 (considered as one shock), 1920/21 (considered as one shock), 1926, 1929, 1931, 1933/34 (considered as one shock), 1940/41/42 (considered as one shock), 1944/45 (considered as one shock), 1975, 1993, 2003, 2008/09. As it is immediately obvious from a look at the data, the size of these shocks is different.

As to the identification of the 'post-recession (recovery) period', the study identifies the period of at least three years, following a shock, without the occurrence of a further recessionary shock. In sum, there are eight 'post-recession' periods: the post recession period following the shock of 1892; the one following the 1910 shock, the one following the 1914/15 shock, the one after the 1920/21 shock, the one after the 19291931-1933/34 shocks, and the ones after the 1944/45 shock, the 1973 shock, the 1993 shock. Of course, there are not sufficient data to consider the recovery from the 2008/09 shock. Some words have to be spent about the length of post-recession period. Fingleton et al. (2011) consider the post-recession recovery lasting until the subsequent shock; such a choice would have implied, in the series under consideration in the present study, that, e.g., the post 1944/45 shock recovery covers the thirty year period until 1974; or the recovery post oil shock in 1975 lasts until 1993. It is hard to define as 'post-shock recovery' a period lasting 18 or 30 years!. For this reason, the present study reports the results pertaining to recovery periods of a fixed length, namely three years. 
Thus, the recovery period after the 1982 shocks covers the years 1893 to 95 , the recovery from the 1910 shock covers the period 1911 to 1913 , and so on. However, the substantial results are robust to this different choice concerning the length of the recovery periods (of fixed length equal to three years, or during until the subsequent shock takes place), in nearly all cases (the two cases in which slightly different results emerge are noted in Table 3).

\section{Insert about here:}

Table 3. - Qualitative results in SURE estimation (general specification)

\subsection{Economic resilience to shocks}

The present analysis starts by considering a regression equation in the form of eq. (1); specifically, it considers the growth rate of per-capita GDP in each of the 16 Italian regions. All series are stationary. For each region this growth rate is regressed against a constant term (which is intended to capture the autonomous regional growth), a set of 14 dummy variables in correspondence to the detected shocks, and a set of 8 dummy variables in correspondence to the detected post-recession periods. The 16 equations are estimated as a system of seemingly unrelated regression equations (SURE). It is worth underlining that this specification perfectly mimics the regression design of Fingleton et al. (2012, eq. (1)) whose results are in their Table 3.

Verbally, the alpha coefficients capture the "autonomous growth", conditional on the reaction to- and recover from- shocks; the beta coefficients capture the specificity of the impact effect of a recessionary shock, upon the regional GDP growth rate; the gamma coefficients capture the possible effect of recovery after shock.

Considering the system estimation, the present interest is in evaluating whether for each shock the beta coefficients are equal across regions: in such a case, there is no "regional specificity" as concerns the impact effect of the shock. Furthermore, if the restriction of equality among coefficients is accepted, the analysis evaluates whether the common coefficient is equal to zero or not: if equal to zero, there is no specific effect of that shock; if it is different from zero, the effect of the shock is significant and equal across regions.

Table 3 reports the qualitative results of the starting, general specification which takes into consideration 14 shocks and 8 recovery periods. Results are a little bit 
surprising, in the sense that several beta and gamma coefficients are statistically insignificant. More specifically, in 8 out of the 14 considered shock cases, the beta coefficients appear to be equal to zero (both if considered as individual coefficients, on the basis of the $t$-statistics, and if considered jointly, on the basis of an appropriate $F$ test): this means that each of these 8 shocks do not show any significant effect on the growth rate of regional GDP. As to the 6 remaining cases, the reaction of regional growth rate to the shocks occurring in 1920/21, 1929, and 1944/45 appears to be statistically significant but equal across regions, according to an appropriate restriction $F$-test; the impact reactions to the shocks occurring in 1914/15, in 1975 and in 1973 appear to be different across regions (and statistically significant).

A similar surprising result emerges with respect to the significance of the recovery dummy variables: the coefficients for post-1982, post-1910, post-1920/21, post-33/34 dummies are equal across regions, and equal to zero (both if considered as individual coefficients in each specific regression equation, and if considered jointly). In the case of post-1914/15, gamma coefficients are statistically significant and equal across regions. Only the post-1944/45 and post-1975 recovery period present dummy variables that are different across regions: more precisely, the test on equality of gamma coefficients rejects the null of equality.

As a consequence of these results, the authors of the present study decided to focus on a regression equation, which retains only a selected group of 6 shocks -called 'major' shocks- and specifically, the shock episodes are retained which show statistical significance for the impact or the recovery dummy variable. Thus, the final regression design considers the following equation :

$$
g_{i}=\alpha_{i}+\sum_{k=1}^{6} \beta_{i(k)} D_{k}+\sum_{k=1}^{6} \gamma_{i(k)} S_{k}+u_{i}
$$

with:

$k=1: 1914 / 15$ shock (and relative recovery);

$k=2: 1920 / 21$ shock (and relative recovery);

$k=3: 1929$ shock (and relative recovery);

$k=4:$ 1944/45 shock (and relative recovery);

$k=5: 1975$ shock (and relative recovery);

$k=6: 1993$ shock (and relative recovery). 
It is important to stress that the distinction between 'major' shocks (as listed above) and other shocks has been left to data, without any discretionary intervention beyond the general (soft) criterion followed, that is, the significance of at least one of the dummy variables associated to the impact or the recovery. This list of major shocks in itself is interesting to comment. A very limited number of recessionary shocks appear to have significant specific effect on regional GDP dynamics: just six episodes over nearly 120 years, included two shocks related to World Wars. ${ }^{5}$ Consider also that some shocks, among the six major selected ones, have displayed a significant effect as far as the dummy variables are concerned, which is equal across regions, so that it is not possible to affirm that different regions have displayed different impact reaction or recovery.

Table 4 reports the results concerning the regression specification (2), with only the six major shocks considered; equations are estimated as a SURE system. All alpha coefficients, capturing the autonomous growth rate, are significant and included in the interval 2.0-2.7\%. ${ }^{6}$ Not surprisingly, beta coefficients are generally negative and significant: in only two cases they are positive, but are not statistically significant, even at the $10 \%$ level; the cases in which beta coefficient are negative, but not significant, include all regional coefficients pertaining to the 1993 shock. The gamma coefficients are generally positive, as expected (in most cases, however, they are not statistically significant); if negative, they are not statistically significant.

\section{Insert about here:}

\footnotetext{
${ }^{5}$ Consider, however, that the 2008/09 shock appear to be insignificant as far as its impact is concerned, but is impossible to evaluate its consequences.

${ }^{6}$ Alpha coefficients show structural break, if considered before and after the II World War; this is far from being a surprise, since the growth rate of GDP has been much larger in the decades after the II World War, as compared to the previous decades. However, the consideration of this structural break does not modify the substantial evidence concerning the coefficients of all other regressors; moreover, no specific reason is available to consider such a structural break in the constant terms. Hence, the regression results in the presence of the break are not printed in this article, but they are of course available from the Authors upon request. Estimations on different sub-samples have also been performed, to check structural stability, and the substantial evidence of the unique regression equation has emerged to be confirmed, as to the significance of dummy variables concerning impact and recovery effects.
} 
Table 4. - Results from the SURE corresponding to eq. (2)

However, the SURE estimation of the set of regression equations (2) could be inefficient as compared to a proper panel data estimation (Singh and Ullah, 1974). Keeping in mind the final goal of evaluating regional specificities in facing common shocks, therefore, the authors of the present study suggest to consider the following model

$$
\begin{aligned}
& g_{i}=\alpha_{i}+\sum_{k=1}^{6} \beta_{i(k)} D_{k}+\sum_{k=1}^{6} \gamma_{i(k)} S_{k}+u_{i} \\
& \alpha_{i}=\alpha_{0}+\varepsilon_{i} \\
& \beta_{i(k)}=\beta_{0(k)}+\zeta_{i(k)} \\
& \gamma_{i(k)}=\gamma_{0(k)}+\tau_{i(k)}
\end{aligned}
$$

where $g_{i}, D_{k}$, and $S_{k}$ maintain the same meaning that they have in equation (1) while respective coefficients are composed by both a deterministic and a random part; deterministic parts are denoted by $\alpha_{0}, \beta_{0}, \gamma_{0}$, while random parts are denoted by $\varepsilon_{i}, \zeta_{i(k)}$, and $\tau_{i(k)}$ with $i=1,2, \ldots 16$.

The analysis is performed using the Random Coefficient Method (RCM). From a methodological perspective RCM represents an expansion (Casetti 1986) of model (1), openly accounting for heterogeneity across subjects -in this case, across regions; hence, it is a natural candidate to make a step ahead from traditional approaches which "deny geography" (Foster 1991, p. 140). Indeed, RCM is a powerful tool in order to deal with potential heterogeneity in resilience and hysteresis among regions: RCM allows to test zero restrictions on $\varepsilon_{i}, \zeta_{i(k)}$, and $\tau_{i(k)}{ }^{7}$ Therefore, in order to test for heterogeneity in the regional resilience according to the RCM framework, the null

\footnotetext{
${ }^{7}$ Multilevel Analysis (MA) has been applied to empirical analysis concerning psychological resilience (e.g.,Ong et al., 2006); psychological resilience is defined as "the capacity of the individual to effectively modulate and monitor an ever-changing complex of desires and reality constraints" (Block and Kremen, 1996, p. 359). However, to the best of the authors' knowledge, this is the first attempt to apply MA to regional economic resilience. More generally, only recently MA has found application to regional economics (Fazio and Piacentino, 2010; Raspe and van Oort, 2007; Torrisi, 2011) while the very recent study on the resilience of U.K. regions of Fingleton et al. (2012), as already mentioned, still adopts a SURE approach to achieve different estimates on regional basis.
} 
hypothesis that the random part of the parameters is zero has been performed. ${ }^{8}$ Furthermore, in order to overcome technical limitations related to the more-than-one random parameter estimation ${ }^{9}$, in lieu of estimating a model with random alpha coefficients, a dummy variable is inserted for each region performing the LR test only on the beta and gamma coefficients. Finally, in line with the precise objective to improve the estimation efficiency, the estimate are considered in which only regressors with statistically significant coefficients are inserted. Results are reported in Table 5.

\section{Insert about here:}

\section{Table 5. - Results from Random Coefficient estimation}

RCM results substantially confirm the resilience story, as told by SURE estimates, with few minor discrepancies. Indeed, as far as the impact (random) coefficients are concerned, only in 1 out of the 3 shocks for which SURE rejects the null of equality at the 5\% significance level (1914/15, 1975 and 1993), regional economies appear to be affected differently, according to the RCM estimation -namely, the 191415 shock. During the remaining recessionary episodes, RCM estimates suggest that shocks impacted all 16 regions considered with equal intensity. Furthermore, as to the three-year recovery periods, RC results are completely consistent with SURE estimates, accepting the null of equality between coefficients for all recovery periods considered, and the statistical insignificance of coefficients in most cases. Roughly speaking, the $\mathrm{RC}$ estimation suggests that the degree of heterogeneity across regions is even more limited, as compared to what emerges from the SURE estimation. Although a more

\footnotetext{
${ }^{8}$ In order to test the heterogeneity in coefficient among regions, a likelihood-ratio (LR) test comparing the fitted mixed model to standard regression with no group-level random effects was performed for each regression. The null hypothesis of the test is that the random part of the parameter is zero. Thus, a rejection of the null hypothesis can be interpreted in the sense that regions do differ in their behaviour with respect to economic shocks.

${ }^{9}$ While the exact distribution of the test is known for the one-random-parameter case (Self and Liang, 1987), an appropriate and sufficiently general computation method for the more-than-one-parameter case has yet to be developed. Therefore, reference distributions for the latter are based on theory (e.g., Stram and Won, 1994) and empirical studies (e.g. McLachlan and Basford, 1988) and related tests are to be considered as conservative.
} 
efficient panel approach allows to refine our interpretation of the resilience story as applied to the Italian regional case-study, the main findings obtained using a SURE approach rest unchanged, showing that the roots of Italian regional differences and consequent dualism, could not be explained in terms of differences in the impact and/or recovery behaviour of regional economies.

Lastly, a few words have to be spent about the equation structural stability. Given the regression design at hand, it is pointless to investigate whether the explanatory dummy variables have an effect which moves over time. On the other hand, it is far from being surprising that a specific constant term covering the years after the II World War would emerge to be positive and significant, provided that the growth in these years is higher than over the previous decades. However, the consideration of such a structural break would not modify the substance of the results concerning the regional coefficients of shock impact and recovery variables: sign, significance and especially the test results about coefficient equality across regions remain robust to the introduction of such a break concerning the constant term. ${ }^{10}$ Similarly, if two separate regressions are run -one covering the period 1890-1945, and one over the period 19462009- the substantial conclusions remain unchanged with respect to the unified regression. For these reasons, the evidence coming from the regression design in the absence of structural break can be considered as reliable.

\section{Performance of Italian regions}

On the basis of statistical description of data, and the results of the present estimation exercises, one can provide clear-cut answers to specific questions concerning the regional growth performance in Italy over the very long run.

\section{Is the growth performance of Italian regions homogenous?}

The income levels across regions differ significantly, as is well known and confirmed by formal test also on the data in the databank at hand; for instance, an ANOVA $F$ test on equality of the mean level across the 16 Italian regions, rejects the null of equality:

\footnotetext{
${ }^{10}$ With reference to the RCM, the introduction of a post 1946 dummy variable makes the coefficients of the recoveries starting in 1930 and in 1993 significant, but no heterogeneity across regions emerges.
} 
$F_{15,1888}=11.067, p=0.000$. The issue about the growth rates is a little bit more involved: indeed, an ANOVA $F$ test would not reject the equality across the mean values of the growth rates across regions $\left(F_{15,1872}=0.131, \mathrm{p}=1.000\right) .{ }^{11}$ However, a formal test on equality of alpha coefficients in regression equation (2) rejects the null of equality. This means that the autonomous growth rates differ across regions, after having controlled for the effect of shocks and recoveries from shock. In other words, the consideration of the occurrence of shocks and post-shock recovery leads to say that regions differ as far as the "autonomous" growth rate is concerned, while in the absence of the explicit consideration of recessionary shock, the growth rates would appear equal across regions (as documented by the ANOVA $F$ test). Provocatively, this enables to say that thanks to shocks, growth rates appear equal across regions: shocks give a contribution to the equality, instead of inequality, of the regional growth rates in Italy.

2. How many recessionary shocks have significant effect on the regional GDP dynamics?

A very limited number of recessionary shocks have emerged to have a significant specific effect on the growth rate of regions, or to have a significant effect in the period of recovery following it. On the basis of statistical significance of dummy variable, only six significant shocks over the period 1890-2009 can be detected.

\section{Have all major shocks the same effect on any given region?}

No, the six considered shocks have different impact effects on any region. This result derives from a series of formal test on the null hypotheses $\beta_{i,(1)}=\beta_{i,(2)}=\ldots=\beta_{i,(6)}$ for each $i$-th region, $i=1,2, \ldots 16$. The result is comprehensible, provided that each shock has specific source, characteristic, intensity, and so on.

4. Has any single major shock a similar or different impact effect on the Italian regions?

\footnotetext{
${ }^{11}$ These pieces of evidence about (dis)equality of levels and equality of growth rates, as they appear from raw data, are not inconsistent and provide a simple story: similar growth rates apply to different levels, so that it is not surprising that the current levels across regions are heterogeneous.
} 
According to the SURE estimation, only three shocks appear to have different impact effect across regions: the 1914/15 shock, the 1975 shock, and the 1993 shock. The 1920/21, 1929 and 1944/45 shock have significant impact upon the regions, but the appropriate test cannot reject that the effect is equal across regions. The degree of heterogeneity across regions, as their impact reaction to common shock is concerned, appears to be even more limited according to the RCM estimator: basing on such estimator, the homogeneity across regions can be rejected only for the 1914/15 shock. From an econometric point of view, the RCM estimator has to be judged as more efficient. The substantial conclusion, however is quite robust: regional differences in reaction to common shock are the exception rather than the rule.

\section{Is the recovery from any single shock equal or heterogeneous across regions?}

In all cases, the recovery effect from any single shock is equal across regions. This result is robust to the consideration of different length of recovery periods, and to different estimators. (By the way, an analogous result, to this respect, emerges in Fingleton et al. (2012) as concerns the employment in the U.K. regions over the last 40 years). In most cases (namely, the recovery periods starting in 1922, 1930, 1976 and 1994), the recovery period dummy variables present coefficients that are not only equal among regions, but also equal to zero, indicating that there is no 'statistically relevant' difference in the recovery years after the shock.

\section{Can the story of different resilience behaviour across Italian regions represent a} sound explanation of the persistent difference in their growth performance?

The answer to this question has to be ' $n o$ ', at least according to the interpretation of the authors of the present study: evidence is provided here that no more than three shocks (in a period of about 120 years) have had a different impact effect on GDP growth rates across regions; the three cases reduce to one if one refers to RCM rather than SURE estimation. In no cases, differences emerge as far as the recovery from shocks is concerned. Hence, it seems that the story of resilience -though conceptually intriguing and worth analyzing- is unable to provide a sound explanation of the persistent differential of growth performances across Italian regions. Of course, the reason of why 
persistent differences across regions remain over the centuries remain open and it is beyond the goal of the present article.

7. Which are the three best (worst) Italian regions, as far as the economic performance is concerned, according to the following criteria: (i) income level, (ii) growth rate, (iii) ability to limit the impact reaction to shock, (iv) the recovery from shocks, $(v)$ the autonomous growth rate (that is, the growth rate conditional on the impact and recovery effects of shocks)?

Clearly, the resilience story can shed new light on these long-debated issues, only as concerns the analysis perspective (iii), (iv) and (v). Nevertheless, prior to deal with such perspectives, it is worth noticing that:

The three regions with the highest GDP average level are: Liguria, Lombardia and Piemonte (the three highest GDP levels at the first decade of our period, 1891-1900, pertain to Lazio, Liguria and Lombardia; the three highest GDP levels in the final decade of our period, 2000-09, pertain to Lombardia, Emilia-R., Lazio. At the opposite end of the list, the three regions with the lowest GDP average level are Calabria, Basilicata and Sicilia (the three lowest GDP levels at the beginning of the period under consideration,1890, pertain to Calabria, Abruzzo and Basilicata; the three lowest GDP levels at the end of the period,2009, pertain to Campania, Calabria and Puglia).

- Over the whole sample under consideration, the three regions with the highest average value of annual growth rate are Veneto, Emilia-R. and Lombardia, while the three regions with the lowest growth rates are Campania, Puglia, Sicilia.

To answer point (iii) one can consider the results of regression equation (2) and look at the size of beta coefficients; in particular:

- Just to curiosity, the lowest beta coefficient (the highest one in absolute value) corresponding to the worst impact effect is associated to the 1944/45 shock in Campania. Of course, to evaluate the general ability of regions to resist to the impact effect of shocks, it makes sense to look at the 'average' level of their beta coefficients. If a simple average of beta coefficients for each regions is computed, the regions showing the smallest negative impact effect emerges to be Sardegna, Umbria and Basilicata; here it is of interest to note that Sardegna is an island, whose economic dynamics are rather unrelated to national industrial shocks, while Umbria and Basilicata 
are small regions: adverse shocks have the most limited negative impact in these regions. At the opposite end of the list, the regions with the highest negative impact effect are Liguria, Lazio and Abruzzo (which are the worst performers as the impact reaction to shock is concerned).

To answer point (iv) one can look at the gamma coefficients and compute the simple average of gamma coefficients pertaining to each region; it is necessary, however, to recall that coefficients are not statistically different across regions, so that the present conclusion is just a 'numerical curiosity' without statistical significance support. In any case, the best recovery performances appear to pertain to Liguria, Piemonte and Lombardia, while the worst ones belong to Calabria, Basilicata and Sicilia. (Consider that a restriction test with the null that the average value of gamma coefficients of Liguria, Piemonte and Lombardia is equal to the average value of gamma coefficients of Calabria, Basilicata and Sicilia gives $\chi_{1}^{2}=3.529$, with $p=0.0603$, so that one can say that the three best performers in recovery show a different performance from the three worst performers, even if only at $6 \%$ significance level.)

- As to the autonomous growth (alpha coefficients), that is, the growth performance after having controlled for the effects of major shocks, the highest values pertain to Veneto, Marche, Abruzzo, while the lowest ones belong to Puglia, Campania, Sicilia.

All these pieces of information, are reported in Table 6, which represents -just to joke- a sort of provocative medal-list for best and worst Italian regions, as far as the economic performance concerns.

\section{Insert about here:}

Table 6. - The resulting medal-list for the Italian regions

8. Is there a relation between the way in which regions react to- and recover fromshocks? Is there a relation between resilience behaviour and general growth performance?

It could be interesting to note that Liguria is the worst performer according to the impact effect of shocks, but the best performer according to the recovery ability; Basilicata is among the best performers as far as the impact reaction is concerned, but among the worst according to the ability to recover. However, this negative trade-off 
between impact and recovery abilities is far from being the rule: Sicily shows a bad performance according to both the impact and the recovery reaction, while Umbria is a good (or very good) performer along both directions, just to mention two opposite cases. Moreover, at first glance, no clear-cut relations emerge between the regional resilience behaviour and the general economic performance. The same conclusion is supported by a simple (and admittedly rough) cross-regional rank correlation analysis between the performance growth, as measured by the average of annual growth rate of per capita GDP, on the one side, and the individual regional coefficients related to resilience on the other side: the cross-regional rank correlation between the average value of per capita GDP growth rate and the average value of beta coefficients is +0.152 (while it should be negative, if one believes that a better impact reaction associates with a better growth performance); the cross-regional rank correlation between the average value of the annual growth rate of GDP and the average value of gamma coefficients is +0.402 : it is positive, as expected on the basis of the guess that a better ability to recover associates with a better growth performance; however, the size of the rank correlation coefficient is rather limited to be a signal of a strong association. The picture is a little bit different if the association is considered between the resilience coefficients and the income levels: the rank correlation between the average value of per capita income and the average value of beta coefficients is equal to -0.270 (which means that a "better" impact reaction to recessionary shock is associated with a higher average income level), while the rank correlation between the average level of per capita income and the average gamma coefficients is equal to +0.930 (or +0.739 if one takes only significant gamma coefficients into consideration): this rank correlation coefficient, in fact, may denote a significant association between the income levels and the ability to recover from recessionary shock, as captured by the gamma coefficients in the regression specifications at hand. Needless to say, the evaluation of these rank correlations is far from being a rigorous analysis. Furthermore, the rank correlation coefficients cannot tell anything about causal links. Thus, it appears correct to conclude that the high-income level regions are able to show a better recovery from shock, rather than to say that a better ability to recover from shock leads to higher income levels. 


\section{Concluding remarks}

This article has evaluated the economic resilience of Italian regions, that is, the regional behaviour in reacting to common shock and in recovering from shock. This study has followed a well established procedure in this (relatively new) research line, especially as concerns the regression analysis design. At the same time, some innovative elements have been introduced; they are worth mentioning: the very long run analysis perspective -the databank under consideration covers about 120 years; the consideration of per capita GDP instead of employment; the efficiency check through proper panel data estimation.

The findings of the present study have documented that Italian regions show a surprisingly low degree of heterogeneity across regions, as far as their reactions to recessionary shocks and recovery from shocks are concerned. Specifically, a very limited number of significantly heterogeneous impact effects have been counted: three cases, or just one case, according to different estimators, over a period longer than a century. Moreover, no regional significant specificities have emerged as far as the recovery from shock is concerned. These pieces of evidence are quite surprising, provided that huge differences characterize Italian regions, and their long-run economic performances.

In sum, this study has arrived at the conclusion that differences in economic resilience are not able to explain the different economic performance of Italian regions with a convincing interpretation. Of course, the reasons of huge and persistent differences in economic performance across Italian regions remains a fascinating issue, that goes beyond the scope of the present study.

\section{REFERENCES}

Barro, R.J., Sala-i-Martin, X. (1991), "Convergence across states and Regions", Brooking Papers on Economic Activity, Vol. 1, pp. 107-57.

Barro, R.J., Sala-i-Martin, X. (1992), “Convergence”, Journal of Political Economy, Vol. 100, pp. 223-51.

Bernard, A., Durlauf, S. (1996), "Interpreting Tests of the Convergence Hypothesis", Journal of Econometrics, Vol. 71, pp. 161-74. 
Block, J.,Kremen, A.M. (1996)“IQ and ego-resiliency: conceptual and empirical connections and separateness", Journal of Personality and Social Psychology, Vol70, pp.349-61.

Brunetti, A., Felice, E., Vecchi, G. (2011), "Reddito" in G. Vecchi (Ed.), In ricchezza e in povertà: Il benessere degli Italiani dall'Unità a oggi, il Mulino, Bologna.

Casetti, E. (1986). "The Dual Expansion Method: An Application for Evaluating the Effects of Population Growth on Development", Systems, Man and Cybernetics, IEEE Transactions, Vol. 16, pp. 29-39.

Cellini, R., Scorcu, A.E. (2007), "How many Italies? What Data Show about Growth and Convergence across Italian Regions, 1970-91", Rassegna di lavori dell'ISCO, Vol. 13, pp. 93-124

Ciccarelli, C., Fenoaltea, S. (2009), La produzione industriale delle regioni d'Italia 1861-1913: Una ricostruzione quantitativa - Le industrie non manifatturiere Vol. 1, Banca d'Italia, Roma.

Ciccarelli, C., Fenoaltea, S. (2010), “Attraverso la lente d'ingrandimento: aspetti provinciali della crescita industriale nell'Italia post-unitaria", Economic History Working Papers Quaderni di Storia Economia, No 4-2010, Banca d'Italia.

D'Amato M., Pistoresi, B. (1997), Statistical Evidence on Regional Cohesion in Italy, Giornale degli Economisti e Annali di Economia, Vol. 56, pp. 211-34.

Daniele, V., Malanima, P. (2007), "Il prodotto delle regioni e il divario Nord-Sud in Italia 18612004”, Rivista di Politica Economica, Vol. 97, pp. 267-316.

De Siano, R. and D'Uva, M. (2008) "Beta-convergence in Italy using a trend break date model", The Empirical Economic Letters, Vol.7, pp.589-596.

Fazio, G. and Piacentino, D. (2010)“A Spatial Multilevel Analysis of Italian SMEs' Productivity”, Spatial Economic Analysis, Vol. 5, pp. 299-316.

Felice, E. (2011a), "The determinants of Italy's regional imbalances over the long run: exploring the contributions of human and social capital", Oxford University Economic and Social History working paper series No. 088, Nuffield College, Oxford University.

Felice, E. (2011b), "Regional value added in Italy over the long run (1891-2001): linking indirect estimates with official figures, and implications", UHE Working Paper 2011_04, Universitat Autonoma de Barcelona.

Fingleton, B., Garretsen, H., Martin R. (2012), "Recessionary Shocks and Regional Employment: Evidence on the Resilience of U.K. Regions", Regional Science, Vol. 52, pp. 109-33.

Foster, S. A. (1991), "The expansion method: Implications for geographic research", The Professional Geographer, Vol. 43, pp. 131-142.

Holling, C. S. (1973), "Resilience and Stability of Ecological Systems", Annual Review of Ecology and Systematics, Vol. 4, pp. 1-23.

Holling, C. S. (1996), "Engineering Versus Ecological Resilience”. In: P. Schulze (Ed.), Engineering within Ecological Constraints, National Academy Press, Washington, DC, pp. $31-44$.

Malanima, P., Zamagni, V. (2010)“150 years of the Italian economy, 1861-2010”, Journal of Modern Italian Studies, Vol. 15, pp. 1-20.

Martin, R. (2012), "Regional Economic Resilience, Hysteresis and Recessionary Shocks", Journal of Economic Geography, Vol. 12, pp. 1-32.

McLachlan, G. J. and. Basford, K.E.(Eds), (1988) Mixture Models, New York, Marcel Dekker.

Ong, A. D., Bergeman, C.S. et al. (2006), "Psychological resilience, positive emotions, and successful adaptation to stress in later life", Journal of Personality and Social Psychology, Vol. 91, pp. 730-49. 
Quah, D. (1996), "Regional Convergence Clusters across Europe”, European Economic Review, Vol. 40, pp. 951-58.

Raspe, O., van Oort, F. (2007), "What when space matters little for firm productivity? A multilevel analysis of localised knowledge externalities", Papers in Evolutionary Economic Geography No. 0706.

Singh, B., Ullah, A. (1974),"Estimation of Seemingly Unrelated Regressions with Random Coefficients", Journal of the American Statistical Association, Vol. 69, pp. 191-195.

Stram, D. O., Won, L.J. (1994), "Variance Components Testing in the Longitudinal Mixed Effects Model”, Biometrics, Vol. 50, pp. 1171-1177.

Torrisi, G. (2011), "A Multilevel Analysis on the Economic Impact of Public Infrastructures and Corruption in Italia Regions", The IUP Journal of Infrastructure, Vol. 9, pp. 17-51.

Tsionas, E.G. (2001), "Regional Convergence and Common, Stochastic Long-run Trends: A Re-examination of the US Regional Data", Regional Studies, Vol. 35, pp. 689-96.

Walker, B., Gunderson, L., Kinzig, A., Folke, C., Carpenter, S., Schultz, L. (2006), “A Handful of Heuristics and Some Propositions for Understanding Resilience in Socio-Ecological Systems", Ecology and Society, Vol. 11 - art. 13. 


\section{FIGURES}

Figure 1. Log of income per capita

(a) in Italy

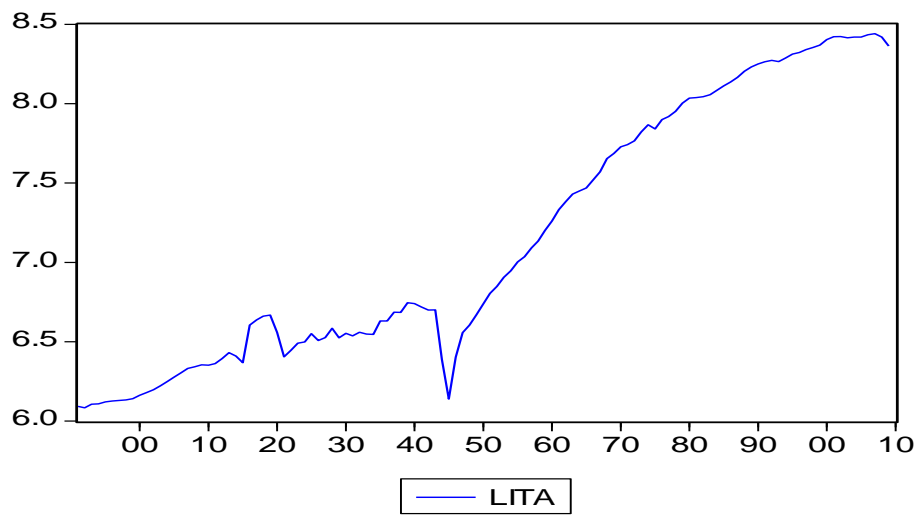

(b) in the 16 Italian regions

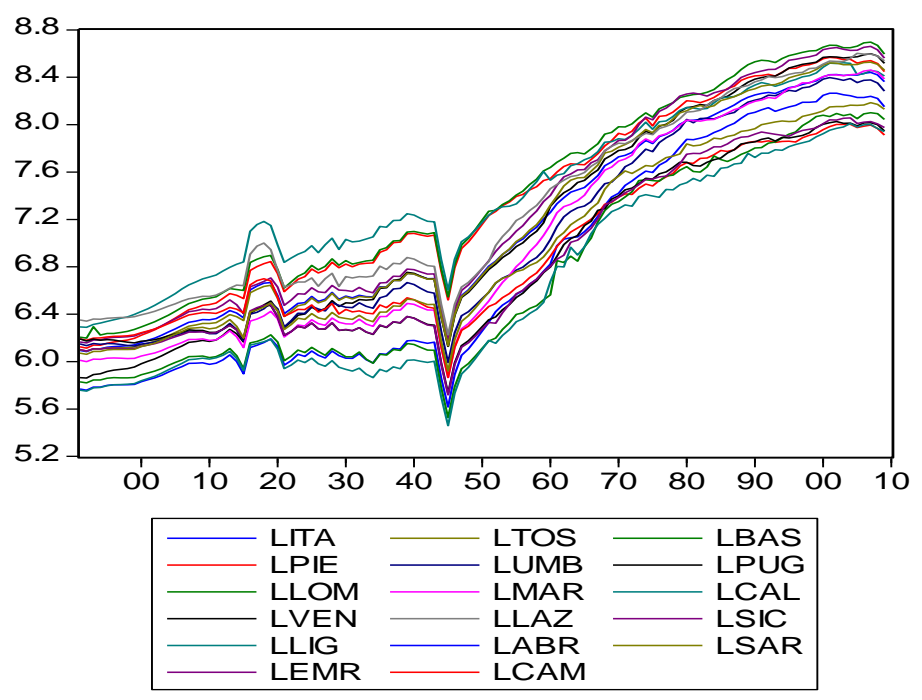

(c) Italy and the two richest and poorest regions

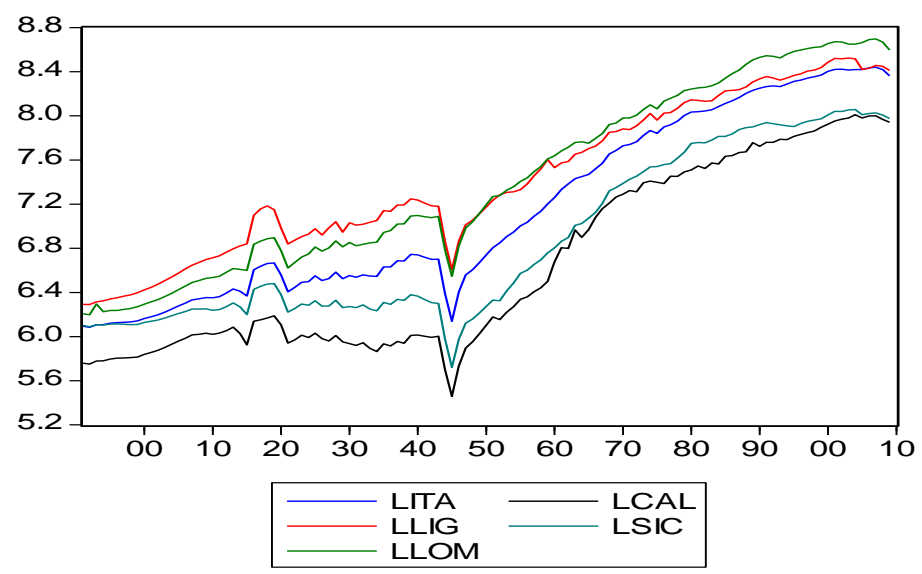


Figure 2. The annual growth rate of income per capita in Italy

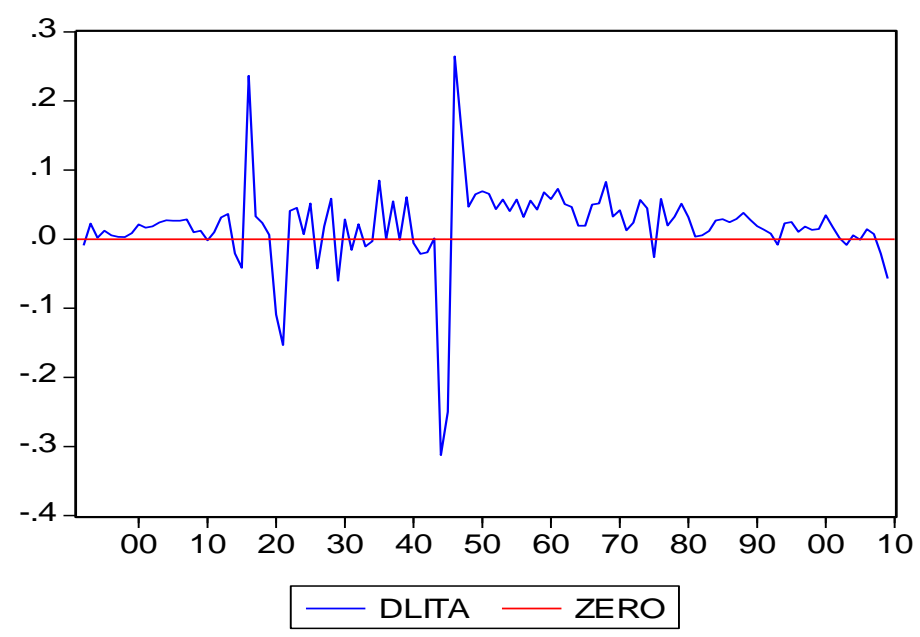




\section{TABLES}

Table 1. Descriptive statistics on time series,Italy and the regions

\begin{tabular}{l|l|rrrrrrr}
\hline & & Mean & Median & Maximum & Minimum & St. Dev. & Skewness & Kurtosis \\
\hline ITA & Italy & 7.148 & 6.745 & 8.440 & 6.084 & 0.814 & 0.341 & 1.535 \\
PIE & Piemonte & 7.348 & 7.160 & 8.568 & 6.113 & 0.807 & 0.130 & 1.602 \\
LOM & Lombardia & 7.413 & 7.194 & 8.696 & 6.197 & 0.828 & 0.192 & 1.586 \\
VEN & Veneto & 7.136 & 6.752 & 8.598 & 5.860 & 0.930 & 0.304 & 1.553 \\
LIG & Liguria & 7.424 & 7.236 & 8.522 & 6.290 & 0.692 & 0.111 & 1.719 \\
EMR & Emilia-R. & 7.267 & 6.784 & 8.660 & 6.157 & 0.877 & 0.363 & 1.512 \\
TOS & Toscana & 7.178 & 6.744 & 8.527 & 6.088 & 0.861 & 0.331 & 1.497 \\
UMB & Umbria & 7.058 & 6.651 & 8.397 & 5.992 & 0.830 & 0.452 & 1.550 \\
MAR & Marche & 7.024 & 6.491 & 8.460 & 5.864 & 0.894 & 0.395 & 1.472 \\
LAZ & Lazio & 7.303 & 6.974 & 8.601 & 6.226 & 0.781 & 0.379 & 1.570 \\
ABR & Abruzzo & 6.801 & 6.257 & 8.265 & 5.618 & 0.924 & 0.445 & 1.507 \\
CAM & Campania & 6.932 & 6.574 & 8.003 & 5.867 & 0.657 & 0.446 & 1.564 \\
BAS & Basilicata & 6.717 & 6.192 & 8.100 & 5.527 & 0.834 & 0.489 & 1.544 \\
PUG & Puglia & 6.861 & 6.438 & 8.025 & 5.730 & 0.721 & 0.466 & 1.511 \\
CAL & Calabria & 6.646 & 6.167 & 8.010 & 5.459 & 0.819 & 0.453 & 1.513 \\
SIC & Sicilia & 6.860 & 6.428 & 8.056 & 5.720 & 0.743 & 0.475 & 1.527 \\
SAR & Sardegna & 6.962 & 6.527 & 8.185 & 5.921 & 0.757 & 0.414 & 1.507 \\
\hline
\end{tabular}

Note: log of income per capita, 1891-2009; 119 obs. 
Table 2. Results on integration and co-integration of regional time series

I. Augmented Dickey-Fuller test

\begin{tabular}{|c|c|c|c|c|c|c|c|}
\hline & $\begin{array}{l}\text { ADF on } \\
\text { level }\end{array}$ & $\begin{array}{l}\text { ADF on } \\
\text { first-difference }\end{array}$ & & & $\begin{array}{l}\text { ADF on } \\
\text { level }\end{array}$ & \multicolumn{2}{|c|}{$\begin{array}{l}\text { ADF on } \\
\text { first-difference }\end{array}$} \\
\hline ITA & -2.050 & $-8.261^{\star *}$ & & & \multirow{2}{*}{\multicolumn{2}{|c|}{$-8130 * *$}} \\
\hline PIE & -2.753 & $-8.601^{* *}$ & \multicolumn{2}{|c|}{ LAZ } & -2.129 & & \\
\hline LOM & -2.649 & $-8.403^{* *}$ & \multicolumn{2}{|c|}{ ABR } & -1.603 & \multicolumn{2}{|c|}{$-8.153^{\star *}$} \\
\hline VEN & -2.037 & $-8.363^{* *}$ & \multicolumn{2}{|c|}{ CAM } & -1.803 & \multicolumn{2}{|c|}{$-8.257^{\star *}$} \\
\hline LIG & -2.988 & $-8.630^{* *}$ & \multicolumn{2}{|c|}{ BAS } & -1.550 & \multicolumn{2}{|c|}{$-9.242^{* *}$} \\
\hline EMR & -1.862 & $-8.256^{* *}$ & PU & & -1.789 & & \\
\hline TOS & 030 & $-8.060^{* *}$ & $\mathrm{CA}$ & & -1.481 & & \\
\hline UMB & 932 & $-8.164^{* *}$ & $\mathrm{SIO}$ & & -1.712 & & \\
\hline MAR & 824 & $-8.164^{\star *}$ & SA & & -1.659 & & \\
\hline II. Group Un & oot tests & & & & & & \\
\hline Test statistics & & Null & Statistic & & p-value & Col & ision \\
\hline Levin, Lin \& Chu & stat & (a) & 2.01 & & 0.9778 & & ccepted \\
\hline Breitung t-stat & & (a) & 5.93 & & 1.0000 & & ccepted \\
\hline Im, Pesaran and & in W-stat & (b) & 6.77 & & 1.0000 & & ccepted \\
\hline ADF - Fisher Chi & uare & (b) & 2.36 & & 1.0000 & & ccepted \\
\hline PP - Fisher Chi-s & are & (b) & 2.13 & & 1.0000 & & ccepted \\
\hline Hadri Z-stat & & (c) & 28.6 & & 0.0000 & $\mathrm{Nul}$ & jected \\
\hline III. Johanse & ace and $\mathrm{l}$ & -Eigenvalue co & ointegr & on tes & & & \\
\hline Hypothesized & & Trace & Crit & & Max-Eigen & Crit & \\
\hline No. of $C E(s)$ & Eigenval & Statistic & alue & Prob. & Statistic & Value & Prob \\
\hline None & 0.9978 & 3772.6 & NA & NA & 696.9 & NA & NA \\
\hline At most 1 & 0.994 & 3075.6 & NA & NA & 585.5 & NA & NA \\
\hline At most 2 & 0.978 & 2490.1 & NA & NA & 436.8 & NA & NA \\
\hline At most 3 & 0.969 & 2053.3 & NA & NA & 397.3 & NA & NA \\
\hline At most 4 & 0.930 & 1656.0 & NA & NA & 303.3 & NA & NA \\
\hline At most 5 & 0.884 & 1352.7 & 34.98 & 0.0000 & 245.83 & 76.58 & 0.0001 \\
\hline At most 6 & 0.844 & 1106.9 & 85.14 & 0.0000 & 211.57 & 70.54 & 0.0000 \\
\hline At most 7 & 0.819 & 895.33 & 39.23 & 0.0001 & 194.39 & 64.50 & 0.0001 \\
\hline At most 8 & 0.729 & 700.94 & 97.37 & 0.0001 & 148.91 & 58.43 & 0.0000 \\
\hline At most 9 & 0.701 & 552.02 & 59.52 & 0.0000 & 137.67 & 52.36 & 0.0000 \\
\hline At most 10 & 0.675 & 414.40 & 25.61 & 0.0000 & 128.04 & 46.23 & 0.0000 \\
\hline At most 11 & 0.509 & 286.36 & 5.753 & 0.0000 & 81.131 & 40.08 & 0.0000 \\
\hline At most 12 & 0.441 & 205.23 & 9.818 & 0.0000 & 66.248 & 33.88 & 0.0000 \\
\hline At most 13 & 0.422 & 138.98 & 7.856 & 0.0000 & 62.499 & 27.58 & 0.0000 \\
\hline At most 14 & 0.287 & 76.489 & 9.797 & 0.0000 & 38.600 & 21.13 & 0.0001 \\
\hline At most 15 & 0.259 & 37.889 & 5.494 & 0.0000 & 34.250 & 14.26 & 0.0000 \\
\hline At most 16 & 0.031 & 3.642 & 8414 & 0.0563 & 3.642 & 3.841 & 0.0563 \\
\hline
\end{tabular}

Sample 1891-2009; 17 time series of log of income per capita are always considered: the 16 regional series and the national one (as listed in Table1). Automatic selection of lags based on SIC.

Panel I: Intercept (and linear trend) are introduced for the test on the first difference (and the level, respectively); ${ }^{* *}\left({ }^{*}\right)$ denotes significance at the $5 \%(10 \%)$ level.

Panel II: The null are: (a) Presence of Unit root (assuming common unit root process); (b) Presence of Unit root (assuming individual unit root process); (c) No unit root (assuming common unit root process); (Laqs between 0 and 2 in all cases);

Panel III: a linear deterministic trend is considered, along with the constant term; lags interval 1 to 4; MacKinnon-Haug-Michelis (1999) p-values; Critical values at the $5 \%$ confidence level. 
Table 3. Qualitative results in SURE estimation (general specification)

\begin{tabular}{|c|c|c|c|}
\hline & (a) & (b) & (c) \\
\hline $\begin{array}{l}\text { Impact effect: } \\
\text { Beta coeffs }\end{array}$ & $\begin{array}{r}\text { All individual beta } \\
\text { coeffs } \\
\text { equal to zero }\end{array}$ & $\begin{array}{r}\text { Equality across } \\
\text { individual beta } \\
\text { coefficients }\end{array}$ & $\begin{array}{r}\text { All beta coeffs equal } \\
\text { to zero } \\
\text { (jointly) }\end{array}$ \\
\hline 1892-shock & OK & OK & $\mathrm{OK}$ \\
\hline 1910-shock & OK & OK & OK \\
\hline 1914/15-shock & ** & ** & $===$ \\
\hline 1920/21-shock & ** & OK & ** \\
\hline 1926-shock & OK & OK & OK \\
\hline 1929-shock & ** & OK & * \\
\hline 1931-shock & OK & OK & OK \\
\hline 1933/34-shock & OK & OK & OK \\
\hline 1940/41/42-shock & OK & OK & OK \\
\hline 1944/45-shock & ** & OK & ** \\
\hline 1975-shock & ** & ** & $==$ \\
\hline 1993-shock & ** & ** & $==$ \\
\hline 2003-shock & OK & OK & OK \\
\hline 2008-09-shock & OK & OK & $\mathrm{OK}$ \\
\hline $\begin{array}{l}\text { Recovery effect: } \\
\text { Gamma coeffs }\end{array}$ & $\begin{array}{l}\text { All individual } \\
\text { gamma coeffs } \\
\text { equal to zero }\end{array}$ & $\begin{array}{r}\text { Equality across } \\
\text { individual gamma } \\
\text { coefficients }\end{array}$ & $\begin{array}{r}\text { All gamma coeffs } \\
\text { equal to zero } \\
\text { (jointly) }\end{array}$ \\
\hline Recovery starting in 1893 & OK & OK & $\mathrm{OK}$ \\
\hline Recovery starting in 1910 & OK & OK & OK \\
\hline Recovery starting in 1916 & ** & OK & ** \\
\hline Recovery starting in 1922 & OK & OK & OK \\
\hline Recovery starting in 1935 & OK & OK & OK \\
\hline Recovery starting in 1946 & ** & $\mathrm{OK}^{\wedge}$ & ** \\
\hline Recovery starting in 1976 & OK & $\mathrm{OK}^{\wedge}$ & OK \\
\hline Recovery starting in 1994 & OK & OK & OK \\
\hline
\end{tabular}

\section{Notes:}

Colum (a) reports whether all individual coefficients are statistically insignificant (at the $5 \%$ significance level): OK means that all coefficients are statistically insignificant; ${ }^{* *}$ means that at least one coefficient is statistically significant; Column (b) reports the result of an $\mathrm{F}$ test on the equality across the coefficients pertaining the 16 regions: OK means that the test accepts the null of equality at the $5 \%$ significance level; ${ }^{* *}$ means that the test rejects the null; Column (c) reports the result of an $\mathrm{F}$ test on joint equality to zero of all the coefficients pertaining the 16 regions: OK means that the null is accepted, * means that the null is rejected, and $==$ means that the test was not performed, since the equality across the coefficients is already rejected.

The results refer to the specification in which the recovery length is a three year period; in the case of recovery lasting till to the subsequent shock, all results remain unchanged, apart from the two cases marked by $\wedge$, in which the equality across regional coefficients is rejected. 
Table 4. Results from the SURE corresponding to eq. (2)

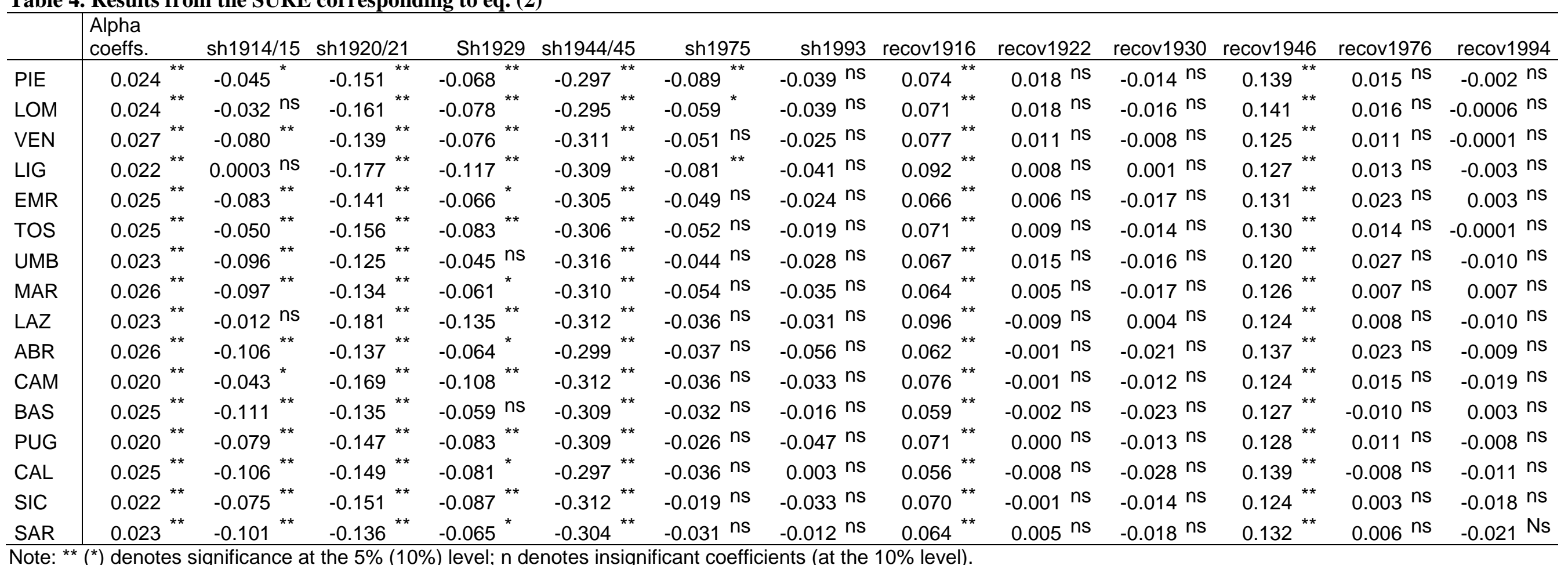


Table 5. Results from Random Coefficient estimation

\begin{tabular}{|c|c|c|c|c|}
\hline & (a) & (b) & (c) & (d) \\
\hline $\begin{array}{l}\text { Shock } \\
\text { (year) }\end{array}$ & $\begin{array}{l}\text { Impact } \\
\text { coefficient } \\
\text { (beta) }\end{array}$ & $\begin{array}{l}\text { Equality in impact } \\
\text { across regions } \\
\text { (zero restrictions } \\
\text { on sigma) }\end{array}$ & $\begin{array}{c}\text { Recovery } \\
\text { coefficient } \\
\text { (gamma) }\end{array}$ & $\begin{array}{l}\text { Equality in recovery } \\
\text { across regions } \\
\text { (zero restrictions } \\
\text { on tau) }\end{array}$ \\
\hline \multirow[t]{2}{*}{$1914 / 1915$} & $-0.070^{\star *}$ & 2.08 & $0.071^{* *}$ & 0.000 \\
\hline & & $(0.075)^{*}$ & & $(1.00)$ \\
\hline \multirow[t]{2}{*}{$1920 / 21$} & $-0.149^{\star \star}$ & 0.000 & $==$ & $==$ \\
\hline & & $(1.00)$ & & \\
\hline \multirow[t]{2}{*}{1929} & $-0.080^{* *}$ & 0.000 & $==$ & $==$ \\
\hline & & $(1.00)$ & & \\
\hline \multirow[t]{2}{*}{$1944 / 1945$} & $-0.306^{* *}$ & 0.000 & $0.130^{* *}$ & 0.000 \\
\hline & & $(1.00)$ & & $(1.00)$ \\
\hline \multirow[t]{2}{*}{1975} & $-0.046^{\star *}$ & 0.000 & $==$ & $==$ \\
\hline & & $(1.00)$ & & \\
\hline \multirow[t]{2}{*}{1993} & $-0.030^{* *}$ & 0.000 & $==$ & $==$ \\
\hline & & $(1.00)$ & & \\
\hline
\end{tabular}

Notes: Column (b) reports the result of an LR test on the zero restriction of random component of impact coefficients for the 16 regions, while Column (d) reports result of an LR test on the similar test on recovery coefficients. P-values reported in parenthesis refer to the distribution of the LR test statistic consisting in a 50:50 mixture of a chi-squared with no degrees of freedom (that is, a point mass at zero) and a chi-squared with 1 degree of freedom (see footnote 7$).{ }^{* *}{ }^{*}$ ) denotes significance at the $5 \%(10 \%)$ level. 
Table 6. The resulting medal-list for the Italian regions

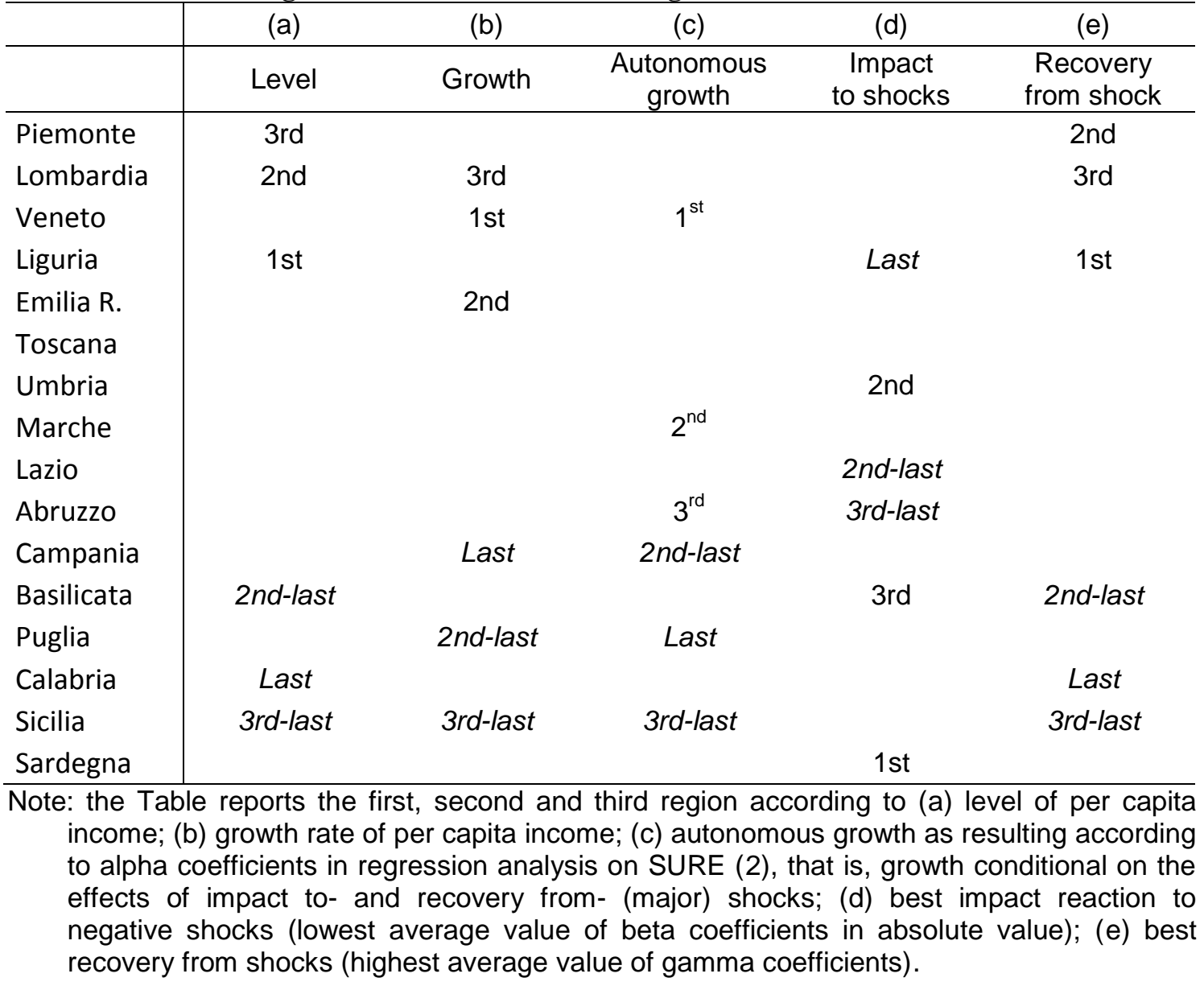

